\section{Comparison of ambulatory blood pressure values in patients with glaucoma and ocular hypertension}

B Yazici', E Usta', H Erturk' and K Dilek²

\begin{abstract}
Purpose To compare systemic arterial blood pressure (BP) and nocturnal hypotension in patients with normal-tension glaucoma (NTG), high-tension glaucoma (HTG), and ocular hypertension.

Methods Systemic BP was recorded by a portable automated BP monitoring device every $20 \mathrm{~min}$ during the day and every $30 \mathrm{~min}$ at night in patients with NTG $(n=18)$, HTG $(n=22)$, and ocular hypertension $(n=19)$. Mean systolic, diastolic, and mean arterial BPs were calculated for $24 \mathrm{~h}$, during the day and at night. The mean and maximum nocturnal dip rates were determined for each patient. The number of readings that declined below $90 \mathrm{mmHg}$ for systolic BP and below 60 and $50 \mathrm{~mm} \mathrm{Hg}$ for diastolic BP was recorded for each group. Statistical significance was set at $P<0.05$.

Results Minimum, maximum, and mean values of the systolic, diastolic, and mean arterial BPs were not significantly different among groups. There was no difference among groups in the nocturnal dip percentages of systolic and diastolic BPs. The number of systolic BP readings below $90 \mathrm{mmHg}$ was significantly higher in the NTG group compared with the other groups $\left(P<0.001, \chi^{2}\right.$ test). Conclusion There may not be any difference among NTG, HTG, and ocular hypertension patients in terms of mean ambulatory $B P$ values. On the other hand, when each individual's ambulatory reading is reviewed, readings may reveal that excessive and repetitive nocturnal drops occur more frequently in some patients with NTG. These hypotensive episodes may be related to the development of glaucomatous damage. Eye (2003) 17, 593-598. doi:10.1038/ sj.eye. 6700436
\end{abstract}

Keywords: ambulatory blood pressure monitoring; nocturnal hypotension normal-tension glaucoma; ocular hypertension

\section{Introduction}

The causes and mechanisms of optic nerve damage in primary open-angle glaucoma are not well delineated. Although intraocular pressure (IOP) is a major pathogenic factor, it does not explain normal-tension glaucoma (NTG) and ocular hypertension.

Haemodynamic changes, independently or in combination with IOP, may play a significant role in the pathogenesis of glaucomatous damage. ${ }^{1-3}$ It has been suggested that decreases in systemic arterial blood pressure (BP) during sleep - nocturnal hypotension - may cause ischaemia of the optic nerve head, particularly in individuals with abnormal vascular autoregulation, and may be related to the underlying vascular aetiology. ${ }^{4,5}$

Although some studies ${ }^{6-8}$ report more prominent nocturnal hypotension in patients with NTG and progressive glaucoma compared with healthy individuals and patients with high-tension glaucoma (HTG), others do not support these findings. ${ }^{4,9}$ In this study, we compared systemic BP values, which were recorded by the ambulatory monitoring method during a 24-h period, in three groups of patients with ocular hypertension, NTG, and HTG for the various parameters.

\section{Materials and methods}

Patients for this study were recruited from the Glaucoma Section of the Department of Ophthalmology, Uludag University, Bursa,
${ }^{1}$ Department of Ophthalmology

Uludag University School of Medicine

Bursa, Turkey

${ }^{2}$ Department of Nephrology Uludag University School of Medicine

Bursa, Turkey

Correspondence:

B Yazici

Department of

Ophthalmology

Uludag University School of Medicine

Gorukle Bursa 16059

Turkey

Tel: + 902244428071

Fax: + 902244428070

E-mail: byazici@

uludag.edu.tr

Received: 23 April 2002 Accepted: 1 November 2002 
Turkey. A total of 59 patients - 19 with ocular hypertension, 22 with HTG, and 18 with NTG-were included in the study. All met the following inclusion criteria:

1. Before starting antiglaucomatous therapy, there should be at least four IOP readings recorded at different times of the day.

2. Before therapy, all IOP readings in patients with NTG should be below $21 \mathrm{mmHg}$.

3. Each patient should have at least four reliable, central 24-2 and/or 30-2 visual field examinations.

4. Evaluation by the Advanced Glaucoma Intervention Study ${ }^{10}$ method should determine a repetitive glaucomatous defect on at least two visual field tests in patients with glaucoma and no defect on any tests in patients with ocular hypertension.

5. Patients should not have any ocular diseases that may cause visual field loss other than glaucoma.

6. No history of neurological trauma, vascular shock, or staying in an intensive care unit.

7. Ambulatory BP monitoring during a $24-\mathrm{h}$ period should be completed without interrupting the patient's sleeping period and comfort.

Demographic data for all three patient groups are shown in Table 1. All the patients were diagnosed first at our clinic, and no other patients referred from outside owing to progressive glaucoma were included in the study.

At Uludag University, follow-up examinations are performed every 3 months for patients with glaucoma and every 6 months for patients with ocular hypertension. Visual field examinations are repeated every 6 months for patients with glaucoma and every year for patients with ocular hypertension.

An ambulatory BP monitoring device (model 90207; Space Labs, Washington, DC, USA) was set to measure BP automatically every 20 min during the day ( 6 am to 11 $\mathrm{pm}$ ) and every $30 \mathrm{~min}$ at night (11 pm to $6 \mathrm{am}$ ). This device, at every measuring, determined the patient's systolic, diastolic, and mean arterial BPs (diastolic $\mathrm{BP}+1 / 3$ (systolic BP-diastolic BP)), and the number of heartbeats and recorded them in its electronic memory. The device was put on the patient's nondominant arm, and he/she was told how it works. Patients were allowed to return home and were recommended to maintain their normal life activities. Patients taking systemic antihypertensive medications were asked to continue taking their medications during the period of recording. After $24 \mathrm{~h}$, the device was taken off and recorded values were transferred to a personal computer. Some readings were considered as non-physiological and rejected if at least one of the following conditions occur: 1) If pulse pressure (difference between systolic BP and diastolic
Table 1 Demographic characteristics of patient groups

\begin{tabular}{lccc}
\hline Patient group & $\begin{array}{c}\text { No. of } \\
\text { patients } \\
\text { (female) } \\
\text { male) }\end{array}$ & $\begin{array}{c}\text { Age, mean } \\
\pm S D \\
\text { (years) }\end{array}$ & $\begin{array}{c}\text { No. of } \\
\text { patients taking/ } \\
\text { not taking } \\
\text { antihypertensive } \\
\text { medications }\end{array}$ \\
\hline $\begin{array}{c}\text { Normal-tension } \\
\text { glaucoma }\end{array}$ & $18(12 / 6)$ & $56.1 \pm 10.0$ & $6 / 12$ \\
$\begin{array}{c}\text { High-tension } \\
\text { glaucoma }\end{array}$ & $22(10 / 12)$ & $63.0 \pm 9.5$ & $5 / 17$ \\
Ocular hypertension & $19(15 / 4)$ & $61.2 \pm 8.7$ & $9 / 10$ \\
\hline
\end{tabular}

$\mathrm{BP}$ ) is less than $10 \mathrm{mmHg}$ when the systolic BP is below $100 \mathrm{mmHg}$; 2) If pulse pressure is less than $10 \%$ of the systolic BP when the systolic BP is above $100 \mathrm{mmHg}$; 3) If diastolic pressure value is above $160 \mathrm{mmHg}$. The device was set to repeat the measurement on such faulty events.

Mean systolic, diastolic, and mean arterial BP values for the 24-h period, day, and night were calculated for each patient. ${ }^{11}$ Each patient's minimum and maximum $\mathrm{BP}$ rates were determined during the entire day, day, and night. By using these values, mean minimum and maximum BPs were calculated for each group. If the highest $\mathrm{BP}$ was recorded on the first or second reading, it was excluded from the analysis because BP tends to be higher at earlier readings.

Nocturnal dip was calculated by using two different formulas:

$$
\text { mean nocturnal dip }=\frac{\text { mean }(\text { daytime }- \text { night time })}{\text { daytime }} \mathrm{BP}
$$

and

$$
\begin{aligned}
& \text { maximum nocturnal dip }= \\
& \frac{(\text { maximum daytime }- \text { minimum night time) }}{\text { maximum daytime }} \mathrm{BP} .{ }^{4,9}
\end{aligned}
$$

Nocturnal dip was calculated separately for each patient and each BP variable. In each group, we also determined the number of readings below $90 \mathrm{mmHg}$ for systolic BP and below 60 and $50 \mathrm{mmHg}$ for diastolic BP. Patients, regardless of their ocular diseases, were divided into two groups according to whether they were taking systemic antihypertensive medications, and nocturnal dip rates were also calculated for each group. Analyses of variance, $\chi^{2}$ test, and Student's $t$-tests were used for statistical analyses. The criterion for determining statistical significance was $P<0.05$.

\section{Results}

The mean patient age in the NTG group was lower than that in the other groups ( $P=0.04$, analysis of variance). 
The percentage of female patients was higher in the NTG and ocular hypertension groups, but the difference was not significant ( $P=0.08, \chi^{2}$ test) (Table 1$)$. Monitoring of $\mathrm{BP}$ was completed at the end of $24 \mathrm{~h}$ in 56 patients; it was repeated in three patients because of sleep disturbance or unusual emotional changes.

Ambulatory BP monitoring results are shown in Table 2. According to the $24-\mathrm{h}$ readings, there was no statistical difference among the three groups for the values of mean systolic, diastolic, and mean arterial BPs. When mean values were calculated separately for daytime and night time, they did not differ significantly among groups. In addition, mean maximum and minimum BP values for the entire day, day, and night were not different among groups (Table 2).

In all groups, mean BPs were significantly lower at night than during the day ( $P<0.001$, Student's $t$-test) (Table 2). However, there was no significant difference among groups for mean nocturnal dip. Maximum nocturnal dip, calculated as the difference between maximum BP during the day and minimum BP at night, was also not different in the three groups.

The nocturnal dip in the mean systolic BP was higher than $10 \%$ in five $(28 \%)$ of 18 patients in the NTG group, six $(27 \%)$ of 22 in the HTG group, and seven $(37 \%)$ of 19 in the ocular hypertension group; the difference was not significant ( $P=0.77, \chi^{2}$ test). The nocturnal diastolic BP dropped more than $10 \%$ in $11(61 \%)$ of 18 patients in the NTG group, eight $(36 \%)$ of 22 in the HTG group, and 10 $(52 \%)$ of 19 in the ocular hypertension group; the difference was not significant $\left(P=0.28, \chi^{2}\right.$ test).

Systolic BP fell below an arbitrary limit of $90 \mathrm{mmHg}$ at any measurement during 24-h monitoring in five patients in each group. However, the frequency of systolic BP falling below this level was significantly higher in the NTG group $\left(P<0.001, \chi^{2}\right.$ test) (Table 3$)$. Whereas systolic readings fell below $90 \mathrm{mmHg} 29$ times in the NTG group, the same situation occurred seven times in the HTG

Table 2 BP values for different periods in the NTG, HTG, and ocular hypertension groups ${ }^{\text {a }}$

\begin{tabular}{|c|c|c|c|c|}
\hline \multirow[t]{2}{*}{ Period and BP parameters } & \multicolumn{3}{|c|}{ Patient group } & \multirow[t]{2}{*}{$\mathrm{P}-$ value $^{\mathrm{b}}$} \\
\hline & NTG & HTG & $\begin{array}{c}\text { Ocular } \\
\text { hypertension }\end{array}$ & \\
\hline \multicolumn{5}{|l|}{$24 h$} \\
\hline Systolic BP & $123.5 \pm 15.9$ & $127.0 \pm 15.7$ & $124.2 \pm 9.4$ & 0.72 \\
\hline Diastolic BP & $75.9 \pm 10.6$ & $75.9 \pm 9.0$ & $74.0 \pm 7.2$ & 0.76 \\
\hline MAP & $93.2 \pm 11.1$ & $94.8 \pm 10.6$ & $92.9 \pm 7.1$ & 0.81 \\
\hline \multicolumn{5}{|l|}{ Day } \\
\hline Systolic BP & $125.6 \pm 15.2$ & $131.0 \pm 15.5$ & $127.1 \pm 10.1$ & 0.49 \\
\hline Minimum systolic BP & $100.5 \pm 13.5$ & $105.9 \pm 15.1$ & $100.0 \pm 12.1$ & 0.31 \\
\hline Maximum systolic BP & $152.2 \pm 20.6$ & $160.4 \pm 22.5$ & $155.5 \pm 17.7$ & 0.45 \\
\hline Diastolic BP & $78.1 \pm 10.5$ & $77.5 \pm 9.5$ & $77.2 \pm 8.5$ & 0.95 \\
\hline Minimum diastolic BP & $58.9 \pm 10.1$ & $57.9 \pm 8.7$ & $56.4 \pm 7.1$ & 0.67 \\
\hline MAP & $95.0 \pm 7.7$ & $95.4 \pm 9.5$ & $97.1 \pm 9.6$ & 0.75 \\
\hline Maximum diastolic BP & $98.2 \pm 15.3$ & $101.0 \pm 13.6$ & $102.6 \pm 14.9$ & 0.64 \\
\hline \multicolumn{5}{|l|}{ Night } \\
\hline Systolic BP & $115.0 \pm 18.9$ & $122.1 \pm 16.0$ & $116.8 \pm 10.6$ & 0.36 \\
\hline Minimum systolic BP & $99.0 \pm 13.6$ & $105.0 \pm 15.6$ & $99.8 \pm 11.0$ & 0.31 \\
\hline Maximum systolic BP & $137.2 \pm 24.6$ & $140.4 \pm 19.3$ & $134.9 \pm 15.6$ & 0.68 \\
\hline Diastolic BP & $69.0 \pm 12.1$ & $69.8 \pm 8.8$ & $67.2 \pm 8.5$ & 0.70 \\
\hline Minimum diastolic BP & $56.1 \pm 11.0$ & $56.5 \pm 8.7$ & $54.0 \pm 8.8$ & 0.67 \\
\hline Maximum diastolic BP & $86.1 \pm 14.5$ & $85.5 \pm 13.1$ & $79.8 \pm 10.6$ & 0.25 \\
\hline MAP & $85.5 \pm 14.5$ & $86.0 \pm 13.3$ & $89.6 \pm 10.9$ & 0.44 \\
\hline \multicolumn{5}{|l|}{ Nocturnal fall (\%) } \\
\hline Systolic BP & $8.8 \pm 5.8$ & $6.8 \pm 4.3$ & $7.9 \pm 6.0$ & 0.53 \\
\hline Diastolic BP & $11.9 \pm 7.4$ & $9.8 \pm 5.2$ & $12.6 \pm 9.3$ & 0.49 \\
\hline MAP & $10.1 \pm 7.1$ & $7.8 \pm 5.1$ & $9.9 \pm 6.6$ & 0.43 \\
\hline \multicolumn{5}{|l|}{ Maximum nocturnal fall (\%) } \\
\hline Systolic BP & $34.4 \pm 8.8$ & $34.1 \pm 7.3$ & $35.2 \pm 9.1$ & 0.92 \\
\hline Diastolic BP & $42.5 \pm 10.1$ & $43.8 \pm 7.0$ & $46.2 \pm 11.4$ & 0.47 \\
\hline
\end{tabular}

aData are given as mean \pm SD mmHg. NTG: normal-tension glaucoma; HTG: high-tension glaucoma; BP: blood pressure; MAP: mean arterial pressure.

${ }^{\mathrm{b}}$ Analysis of variance. 
Table 3 Number of readings below $90 \mathrm{mmHg}$ for systolic and below 50 and $60 \mathrm{mmHg}$ for diastolic BP

\begin{tabular}{lcccc}
\hline $\begin{array}{l}\text { Blood } \\
\text { pressure } \\
(\text { mmHg })\end{array}$ & $\begin{array}{c}\text { Normal-tension } \\
\text { glaucoma } \\
(\mathrm{n}=1043)\end{array}$ & $\begin{array}{c}\text { Nigh-tension } \\
\text { glaucoma } \\
(\mathrm{n}=1331)\end{array}$ & $\begin{array}{c}\text { Ocular } \\
\text { hypertension } \\
(\mathrm{n}=1164)\end{array}$ & \\
\hline Systolic $<90$ & 29 & 7 & 9 & $<0.001$ \\
Diastolic $<60$ & 103 & 150 & 134 & 0.42 \\
Diastolic $<50$ & 20 & 19 & 16 & 0.53 \\
\hline
\end{tabular}

${ }^{\mathrm{a}} \chi^{2}$ test.

group and nine times in the ocular hypertension group. Four patients in the NTG group, one in the ocular hypertension group, and none in the HTG group had at least three or more systolic readings of less than $90 \mathrm{mmHg}$. Diastolic readings less than $50 \mathrm{mmHg}$ were also more frequent in the NTG group, but the difference was not significant (Table 3). Four of five patients with NTG in whom systolic BP dropped frequently and deeply were women, and their ages ranged from 41 to 52 years. The other patient was a 61-year-old man.

Of 59 patients, 20 were taking systemic antihypertensive medications. In this group, mean \pm SD systolic and diastolic nocturnal dips were $9.1 \pm 5.4 \%$ and $12.4 \pm 9.0 \%$, respectively. These values were $7.2 \pm 5.2 \%$ and $10.9 \pm 6.7 \%$ in the group not taking antihypertensive medications; the differences between the two groups were not significant $(P=0.24$ and 0.48 , unpaired Student's $t$-test).

A power calculation based on the mean value, standard deviation, and sample size was performed with an alpha-error of 0.05 for each variance analysis. NCSS 2000/PASS statistical software was used. The power of study ranged from 0.06 to 0.30 .

\section{Discussion}

Several systemic and local vascular changes, which might reduce blood flow to the optic nerve, may be associated with primary open-angle glaucoma. ${ }^{12-14}$ Recent studies have indicated that blood flow regulatory mechanisms may be deficient in patients with glaucoma, particularly in the subgroup with NTG. ${ }^{15-17}$ In most people, systemic arterial BP decreases physiologically during sleep. A marked nocturnal fall in BP, particularly if autoregulation capacity is diminished, may lead to ischemic damage in the optic nerve head. ${ }^{4}$

Previously, in several studies, patients with NTG were compared with other patients with HTG, ocular hypertension, or anterior ischemic optic neuropathy and healthy individuals based on 24-h ambulatory BP monitoring results. Graham et $a l^{9}$ did not find a significant difference between patients with NTG and
HTG for nocturnal dip and mean BP values. Patients showing systolic and diastolic dip of more than $10 \%$ were in similar proportion in both NTG and HTG groups. However, regardless of their disease, when patients were classified based on visual field progression, a greater nocturnal dip, both systolic and diastolic, was observed in the progressive group than in the stable group. Also, Hayreh et $a l^{4}$ did not find any difference between the NTG group and the HTG, anterior ischemic optic neuropathy, and ocular hypertension groups for mean nocturnal dip and other BP variables. The only exception is that the mean diastolic BP at night is lower and nocturnal diastolic dip is more significant in the NTG group than in the anterior ischemic optic neuropathy group. In this study, no difference was observed in nocturnal hypotension and other BP variables between patients with stable and progressive visual field loss. In agreement with the previous two studies, ${ }^{4,9}$ we did not find any difference in the groups with NTG, HTG, and ocular hypertension for the mean nocturnal dip and daytime BP values. In our study, the number of visual field tests was not sufficient to judge progression in each patient, so a comparison between the progressive and stable glaucoma groups could not be made.

Some studies have reported deeper nocturnal hypotension in the NTG group compared with the HTG group and controls. Meyer et $a l^{6}$ compared 20 patients with NTG with 20 healthy individuals and found a more prominent nocturnal fall in patients with NTG. In this study, when patients with NTG were divided into two groups - with or without focal ischemic signs - no difference was found between the two subgroups for mean BP values. Kaiser et $a l^{7}$ reported lower systolic BP, during the day and at night, in patients with NTG than in healthy individuals. The same finding is also true for patients with HTG who had visual field progression despite IOP control. In the study by Bechetoille and Bresson-Dumont, ${ }^{8}$ mean systolic and diastolic BPs in NTG, during the day and at night, are significantly lower than in HTG. In our study, there was no difference in mean BP values in the NTG, HTG, and ocular hypertension groups. The mean daytime and night time values for each group were within the normal limits reported in the literature for healthy subjects. ${ }^{18}$

The disagreement among the previous studies may be related to differences in patient and control group compositions. In addition, different criteria and analysing methods have been used in calculating nocturnal fall. ${ }^{4,6,9}$ In our study, we calculated nocturnal fall with two different formulas, which were used by Graham et $a l^{9}$ and Hayreh et $a l_{;}^{4}$ there was no difference among the results.

The method used in the previous studies to measure nocturnal hypotension is to calculate the differences 
between mean BP values in the day and at night. This method, which is used frequently by cardiologists and internists, may not be appropriate for evaluating nocturnal hypotension in optic nerve ischemic disorders. ${ }^{19}$ Since high and low values of the BP neutralize each other using this method, the information on transient, deep hypotension moments may be completely lost. However, transient falls in BP below the critical autoregulation range of blood flow in the optic nerve head may be enough to precipitate an ischemic episode. ${ }^{19}$ The results of our study support this criticism of the method. Although the groups were not different in terms of mean BP values, analysis of each reading revealed that deep systolic BP falls occur more frequently in patients with NTG. The systolic BP dropped below the limit of $90 \mathrm{mmHg}$ at least three times in $22 \%$ of patients with NTG (four of 18 patients), in only $5 \%$ of those with ocular hypertension (one of 19 patients), and in none of those with HTG. Graham et $a l^{9}$ noted a similar finding in $30 \%$ of patients (11 of 37 patients) with progressive glaucoma. Interestingly, these patients were 10 years younger, on average, than the other group, as in our study. Although systemic BP is relatively lower in the younger age group, we think that frequent and deep systolic pressure falls in some glaucoma patients could not be explained by age difference. Such a steep age-dependent fall in BP is quite unlikely. Moreover, despite age differences, there was no significant difference between the groups for mean pressure levels and nocturnal fall in our study.

In our study, the number of patients taking systemic antihypertensive medications was relatively higher in the ocular hypertension group. Possibly, the untreated BP values were relatively higher in this group, as reported by the previous studies. ${ }^{12,13}$ In this study, the patient groups taking and not taking antihypertensive medications did not differ for nocturnal dip rates significantly. However, it should be considered that some systemic antihypertensive drugs may exaggerate nocturnal hypotension. ${ }^{19}$

Systemic BP, which is measured on the brachial artery, does not provide direct information about capillary blood flow at the optic nerve head. However, Grunwald et $a l^{20}$ measured circulatory variables in the neuroretinal rim and in the optic cup with a laser Doppler flowmeter and found that there is a significant correlation between optic nerve head blood flow and brachial BP. Glaucoma patients without systemic hypertension had a $26 \%$ lower average blood flow than patients with systemic hypertension. In our study, ambulatory BP monitoring showed that deep and repetitive falls in systemic BP occur more frequently in patients with NTG. If each individual ambulatory reading is not reviewed, this finding may be missed. Marked nocturnal falls in systemic BP, in the presence of other risk factors, may result in an insufficient blood supply to the optic nerve head. This study supports the hypothesis that nocturnal hypotension may play a role in the development of glaucomatous damage.

\section{References}

1 Flammer J. To what extent are vascular factors involved in the pathogenesis of glaucoma? In: Kaiser HJ, Flammer J, Hendrickson P (eds). Ocular Blood Flow: New Insights into the Pathogenesis of Ocular Diseases. Karger: Basel, Switzerland, 1996, pp 12-39.

2 Van Buskirk EM, Cioffi GA. Glaucomatous optic neuropathy. Am J Ophthalmol 1992; 113: 447-452.

3 Drance SM. Glaucoma: a look beyond intraocular pressure. Am J Ophthalmol 1997; 123: 817-819.

4 Hayreh SS, Zimmerman MB, Podhajsky P, Alward WL. Nocturnal arterial hypotension and its role in optic nerve head and ocular ischemic disorders. Am J Ophthalmol 1994; 117: 603-624.

5 Hayreh SS. Systemic arterial blood pressure and the eye. Eye 1996; 10: 5-28.

6 Meyer JH, Brandi-Dohrn J, Funk J. Twenty-four hour blood pressure monitoring in normal tension glaucoma. $\mathrm{Br} \mathrm{J}$ Ophthalmol 1996; 80: 864-867.

7 Kaiser HJ, Flammer J, Graf T, Stumpfig D. Systemic blood pressure in glaucoma patients. Graefes Arch Clin Exp Ophthalmol 1993; 231: 677-680.

8 Bechetoille A, Bresson-Dumont H. Diurnal and nocturnal blood pressure drops in patients with focal ischemic glaucoma. Graefes Arch Clin Exp Ophthalmol 1994; 232: 675-679.

9 Graham SL, Drance SM, Wijsman K, Douglas GR, Mikelberg FS. Ambulatory blood pressure monitoring in glaucoma: the nocturnal dip. Ophthalmology 1995; 102: 61-69.

10 The Advanced Glaucoma Intervention Study Investigators. Advanced Glaucoma Intervention Study 2: visual field test scoring and reliability. Ophthalmology 1994; 101: 1445-1455.

11 O'Brien E, Coats A, Owens P, Petrie J, Mee F, Padfield PL et al. Use and interpretation of ambulatory blood pressure monitoring: recommendations of the British Hypertension Society. BMJ 2000; 320: 1128-1134.

12 Tielsch JM, Katz J, Sommer A, Quigley HA, Javitt JC. Hypertension, perfusion pressure and primary open-angle glaucoma: a population-based assessment. Arch Ophthalmol 1995; 113: 216-221.

13 Leske MC, Pogdor MJ. Intraocular pressure, cardiovascular risk variables and visual field defects. Am J Epidemiol 1983; 118: $280-287$.

14 Harris A, Sergott RC, Spaeth GL, Katz JL, Shoemaker JA, Martin BJ. Color Doppler analysis of ocular vessel blood velocity in normal-tension glaucoma. Am J Ophthalmol 1994; 118: $642-649$.

15 Evans DW, Harris A, Garrett M, Chung HS, Kagemann L. Glaucoma patients demonstrate faulty autoregulation of ocular blood flow during posture change. $\mathrm{Br} J$ Ophthalmol 1999; 83: 809-813.

16 Ulrich A, Ulrich C, Barth T, Ulrich WD. Detection of disturbed autoregulation of the peripapillary choroid in 
primary open angle glaucoma. Ophthalmic Surg Lasers 1996; 27: 746-757.

17 Kaiser HJ, Flammer J, Wenk M, Lüscher TF. Endothelin-1 plasma levels in normal-tension glaucoma: abnormal vascular response to postural changes. Graefes Arch Clin Exp Ophthalmol 1995; 233: 484-488.

18 Staessen JA, Fagard RH, Lijnen PJ, Thijs L, Van Hoof R, Amery AK. Mean and range of the ambulatory pressure in normotensive subjects from a meta-analysis of 23 studies. Am J Cardiol 1991; 67: 723-727.

19 Hayreh SS, Podhajsky P, Zimmerman MB. Role of nocturnal arterial hypotension in optic nerve head ischemic disorders. Ophthalmologica 1999; 213: 76-96.

20 Grunwald JE, Piltz J, Hariprasad JD, Maguire MG. Optic nerve blood flow in glaucoma: effect of systemic hypertension. Am J Ophthalmol 1999; 127: 516-522. 